\title{
LETRA VS. EQUIVALÊNCIA NA TRADUÇÃO DE PROVÉRBIOS E EXPRESSÕES IDIOMÁTICAS
}

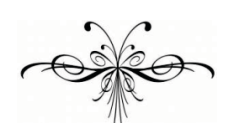

REGINALDO FRANCISCO

\section{Resumo}

Neste trabalho, partindo da proposta de Berman (2007) de uma tradução voltada para a "letra" de provérbios e expressões idiomáticas, buscamos demonstrar como essa posição representa uma ruptura em relação ao que defende a maioria dos estudiosos do assunto. Nos textos analisados, é possível observar que, além de priorizar a tradução voltada para a busca de equivalentes, na maioria das vezes os autores sistematicamente ignoram a opção de utilizar uma tradução próxima à literal, no sentido apresentado por Berman (2007).

Palavras-chave: Provérbios. Expressões Idiomáticas. Berman. Tradução da Letra.

\begin{abstract}
This paper seeks to demonstrate how Berman's (2007) proposal of a translation concerned with the "letter" of proverbs and idioms can represent a departure from what is defended by most translation scholars. It is possible to observe in the texts that, apart from prioritizing translation based on a search for equivalents, most authors systematically ignore the option of creating a close-toliteral translation as proposed by Berman (2007).
\end{abstract}

Keywords: Proverbs. Idioms. Berman. Translation of the Letter. 
$\mathrm{O}$ teórico e crítico de tradução francês Antoine Berman, em seu livro $A$ tradução e a letra ou o albergue do longínquo, resultante de um seminário realizado em 1984 no Collège International de Philosophie, em Paris, faz uma defesa contundente da tradução da "letra" do texto original, ou seja, aquela que tem sua "atenção voltada para o jogo de significantes” (BERMAN, 2007, p. 16). Apesar disso, o autor tem consciência de que a maior parte das traduções realizadas tanto atualmente como no passado não seguem esse posicionamento, assim como a maioria das teorias a respeito.

Berman (2007) afirma que as traduções literárias em suas formas tradicionais e dominantes representam um ato culturalmente etnocêntrico, isto é, "que traz tudo à sua própria cultura, às suas normas e valores, e considera o que se encontra fora dela - o Estrangeiro - como negativo ou, no máximo, bom para ser anexado, adaptado, para aumentar a riqueza desta cultura" (p. 28). Afirma ainda que esse tipo de tradução busca "fazer com que a esqueçam", fazer com que "não se "sinta' a tradução", evitando "chocar com 'estranhamentos' lexicais e sintáticos” (p. 33, grifo do autor). Ecoando o texto clássico de Schleiermacher (1813/2007) ${ }^{1}$, afirma ser um dos princípios da tradução etnocêntrica que "a tradução deve oferecer um texto que o autor estrangeiro teria escrito se tivesse escrito na língua da tradução" (BERMAN, 2007, p. 33). ${ }^{2}$

Para se opor à tradução etnocêntrica dominante, o autor propõe a prática de uma tradução ética, cujo objetivo estaria em "reconhecer e em receber o Outro enquanto Outro" (ibid., p. 68), em lugar de esconder o elemento estrangeiro da obra traduzida. Para esse propósito defende uma tradução literal, fiel à "letra" do original, o que para ele representaria a "essência última e definitiva da tradução": "Partimos do seguinte axioma: a tradução é tradução-da-letra, do texto enquanto letra" (ibid., p. 25, grifo do autor). Assim, para o autor, não teria cabimento uma fidelidade ao sentido ou ao "espírito" da obra.

O objetivo ético do traduzir, por se propor acolher o Estrangeiro na sua corporeidade carnal, só pode estar ligado à letra da obra. Se a forma do objetivo é a fidelidade, é necessário dizer que só há fidelidade — em todas as áreas — à letra. Ser 'fiel' a um contrato significa

\footnotetext{
${ }^{1}$ Ueber die verschiedenen Methoden des Uebersetzens, de 1813. Aqui utilizamos a tradução de 2007 para o português, Dos diferentes métodos de traduzir, realizada pelo Prof. Dr. Mauri Furlan, ainda não publicada.

${ }^{2}$ Venuti $(1995 ; 2002)$ também denuncia essa prática nas culturas anglófonas. A principal diferença entre as reflexões dos dois autores é que Venuti $(1995 ; 2002)$ encara tal postura como de importância política, destacando seus prováveis efeitos para as relações culturais e até diplomáticas entre as nações, assim como para a visibilidade e a valorização da figura do tradutor, enquanto Berman (2007) trata a questão do ponto de vista da ética. A ênfase na abordagem de Berman (2007) neste trabalho se deve à sua referência à tradução de provérbios e locuções.
} 
respeitar suas cláusulas, não o 'espirito' do contrato. Ser fiel ao 'espirito' de um texto é uma contradição em si (ibid., 2007, p.70).

É importante ressaltar que a fidelidade à letra proposta por Berman (2007) não deve ser confundida com uma tradução "palavra por palavra". A letra de um texto, para ele, não se restringe às suas palavras; envolve também, como ele exemplifica ao tratar da tradução de provérbios, ritmo, comprimento, possíveis aliterações, etc. (ibid., p. 16).

\section{Os provérbios e "locuções"}

Um exemplo utilizado por Berman (2007) para indicar o que seria (e o que não seria) traduzir da forma como ele propõe é a tradução de provérbios e "locuções" (veremos mais adiante como esse termo é utilizado pelo autor de maneira abrangente). Nesse ponto fica bem claro o significado para ele de uma tradução voltada para a letra, conforme assinala em relação aos provérbios, por exemplo: "traduzir literalmente um provérbio não é simplesmente traduzir 'palavra por palavra'. É preciso também traduzir o seu ritmo, o seu comprimento (ou sua concisão), suas eventuais aliterações etc. Pois um provérbio é uma forma" (p. 16).

Os provérbios são mencionados logo no início de sua argumentação. Por repousarem em experiências a princípio semelhantes, normalmente apresentam correspondentes em outros idiomas, embora às vezes com imagens diferentes. Provavelmente com base nisso, os tradutores que participavam do seminário que originou o livro acreditavam, como conta o autor, que traduzir um provérbio seria sempre encontrar o seu equivalente ${ }^{3}$, concepção contestada por Berman (2007).

Os tradutores que assistiram ao seminário, na maioria, rejeitavam tal "ótica" [da tradução atenta ao jogo dos significantes do original]. Para eles, compulsivamente, traduzir significava encontrar equivalentes. [...] O caso dos provérbios pode parecer insignificante, mas é altamente simbólico. Ele revela toda a problemática da equivalência. Pois procurar equivalentes não significa apenas estabelecer um sentido invariante, uma idealidade que se expressaria nos diferentes provérbios de lingua a língua. Significa recusar introduzir na lingua para a qual se traduz a estranheza do provérbio original [...], significa recusar fazer da lingua para a qual se traduz. "o albergue do longínquo", significa, para nós, afrancesar:

\footnotetext{
${ }^{3}$ Apesar de Berman (2007) não se preocupar em definir seu conceito de "equivalência", sentimos algum desconforto em utilizá-lo sem uma delimitação teórica, sendo o termo objeto de tantas discussões no campo dos Estudos da Tradução. A nosso ver, sua problemática tem raízes já na sua etimologia, por remeter à ideia de "igual valor", condição quase sempre inalcançável entre elementos de diferentes complexos língua-cultura. Todavia, como a maioria dos autores citados utiliza o conceito, consideramos conveniente mantê-lo, reportando-nos à definição clássica de Vinay e Darbelnet (1958), para quem a equivalência seria uma formulação diferente para uma mesma situação (p. 8-9).
} 
velha tradição. Para o tradutor formado nesta escola, a traducão é uma transmissão de sentido que, ao mesmo tempo, deve tornar este sentido mais claro, limpá-lo das obscuridades inerentes à estranheza da língua estrangeira. (p. 17, grifos do autor)

Mais adiante, Berman (2007) inclui a "destruição das locuções" em sua lista das "tendências deformadoras" da tradução, e demonstra ser também nesse caso favorável a uma tradução voltada para a letra. Além disso, na sequência esclarece como acredita poder o leitor da tradução compreender o sentido do provérbio estrangeiro traduzido literalmente, por meio de uma "consciência-de-provérbio" que os falantes de qualquer idioma possuiriam.

Ora, ainda que o sentido seja idêntico, substituir um idiotismo pelo seu equivalente é um etnocentrismo [...] Servir-se da equivalência é atentar contra a falância da obra. As equivalências de uma locução ou de um provérbio não os substituem. Traduzir não é buscar equivalências. Ademais, querer substitui-las significa ignorar que existe em nós uma consciência-de-provérbio que perceberá imediatamente no novo provérbio, o irmão de um provérbio local. (BERMAN, 2007, p. 60, grifos do autor)

Assim, empregar um equivalente nesses casos significaria limitar o leitor, impedi-lo de ter contato com uma riqueza do texto estrangeiro e conhecer novas formas de expressão. Porém antes de continuarmos a tratar das possibilidades de tradução dessas ocorrências, faz-se necessário esclarecer melhor o sentido do termo "locução".

\section{A (in)definição das "locuções" de Berman}

Não sendo este o ponto central da reflexão de Berman (2007), o autor não se preocupa em apresentar a definição de "locução" ou em ser homogêneo em relação à terminologia sobre o assunto. $\mathrm{Na}$ última citação acima, por exemplo, é possível notar que "locuções" e "idiotismos" são utilizados quase intercambiavelmente. Além disso, os próprios provérbios acabam inseridos no conceito de locução, pois o autor os menciona nessa mesma citação e, logo em seguida, oferece equivalentes de um provérbio em várias línguas, e tudo isso dentro do tópico intitulado "A destruição das locuções".

Já no início desse tópico, aliás, Berman (2007) faz menção aos diversos tipos de fenômenos aos quais se refere: "A prosa abunda em imagens, locuções, modos de dizer, provérbios etc., que dizem respeito ao vernacular. A maioria deles veicula um sentido ou uma experiência que se encontram em locuções etc., de outras línguas" (p. 59).

Isso posto, poderíamos trabalhar aqui com um conceito amplo como "lexias complexas", conforme utilizado em Francisco e Zavaglia (2008), em que são abordadas todas essas sequências de palavras que constituem "um 
todo inseparável, com um sentido único global que não resulta da soma dos sentidos das partes que o compõem" (p. 56). Nesse trabalho, no entanto, é utilizado esse termo geral porque se discute uma possibilidade de "armadilha" para o tradutor que seria comum para todas as lexias complexas: a "não identificação por parte do tradutor da lexia complexa como uma unidade de sentido indecomponível" (p. 69).

No entanto, no presente trabalho extrapolaríamos nosso objetivo se fôssemos discutir a tradução das lexias complexas em geral, pois estaríamos tratando de formas extremamente variadas, indo desde "com certeza" ou "de fato" até "De cavalo dado não se olha os dentes" ou "Quem tudo quer nada tem". Assim, trabalhar com um conceito tão amplo dificultaria qualquer comparação com os demais autores estudados, de forma que preferimos nos ater a expressões idiomáticas e provérbios.

\section{Expressões idiomáticas e provérbios}

Nem sempre os autores citados compartilham da mesma delimitação do que sejam expressões idiomáticas ou provérbios. Entretanto, convém explicitarmos quais foram os conceitos adotados neste trabalho.

Nossas concepções de expressão idiomática e de provérbio são adotadas dos trabalhos de Xatara (1998) e Succi (2006), respectivamente. Assim, aceitamos expressão idiomática como uma "lexia complexa indecomponível, conotativa e cristalizada em um idioma pela tradição cultural" (XATARA, 1998, p. 17) 4 e provérbio como

UL [unidade lexical] fraseológica relativamente fixa, consagrada por determinada comunidade linguistica que recolhe experiências vivenciadas em comum e as formula em enunciados conotativos, sucintos e completos, empregando-os como um discurso polifônico de autoridade por encerrar um valor moral atemporal ou verdades ditas universais e por representar uma tradição popular transmitida até milenarmente entre as gerações. (SUCCI, 2006, p. 31)

Também são úteis as distinções de Ferraz e Souza (2004), estabelecendo um complemento por negação das definições acima. Considerando o "caráter eminentemente conotativo" das expressões idiomáticas, as autoras diferenciam-nas de outras lexias: das locuções ("às pressas”), das combinatórias usuais ("perdidamente apaixonado"), das perífrases verbais ("dar um passeio"), dos ditados ("amor com amor se paga"), dos sintagmas terminológicos ("válvula redutora de pressão") e dos coletivos ("constelação de estrelas") (p. 145).

\footnotetext{
${ }^{4}$ Também aceitaremos, como essa autora, expressões idiomáticas e idiomatismos como sendo sinônimos.
} 
Pela mesma característica semântica Succi (2006) e Xatara e Succi (2008) distinguem provérbios e ditados: estes, ao contrário daqueles, não são conotativos. Dessa forma, "Quanto mais se tem, mais se quer" seria um ditado, pois seu sentido é denotativo, enquanto "Em terra de cego, quem tem um olho é rei" seria um provérbio, por ser conotativo.

A mesma autora, porém, em outro trabalho (Xatara, 1994), comenta as dificuldades para realizar essas conceituações e afirma não serem as definições consensuais:

o termo expressão idiomática, ao lado de idiomatismo, parece-me consagrado, embora não seja muito adequado, pois seu sentido etimológico é amplo demais e, justamente por isso, bastante impreciso.

Além disso, há termos vizinhos que provocam confusão: Galisson (1984) considera expressões idiomáticas sinônimos de frases feitas e de locuçôes figuradas. Locuções on expressões idiomáticas são utilizadas indiferentemente por Diaz. (1984); Rwet (1983), Danlos (1981) e Gross (1982) falam apenas em expressões ou frases cristalizadas (figèes).

(XATARA, 1994, p. 22, grifos da autora)

O mesmo é apontado em Xatara e Succi (2008) em relação aos provérbios:

Normalmente o provérbio é tomado, pelos leigos, por designações genéricas ou pretensamente sinônimas, mas se observarmos as definições de provérbio e de outros fraseologismos propostas por lexicógrafos e fraseólogos renomados (OLIVEIRA, 1991; SILV A, 1992; ROCHA, 1995; VELLASCO, 2000; HOUAISS, 2001; BRAGANCA JÚNIOR, 2003), poderemos constatar que os vários fraseologismos tidos como "sinônimos" de provérbio ora se distanciam, ora se aproximam entre si. (p. 33)

De fato, foi possível observar na bibliografia consultada que as concepções do que seriam expressões idiomáticas e provérbios variam muito, apesar de todos os autores empregarem essas nomenclaturas. Tais divergências, porém, não prejudicam nosso trabalho, uma vez que os diferentes conceitos dos outros autores, mesmo quando não explicitados, demonstram ser mais abrangentes que os propostos por Xatara (1998), de modo que podemos levar em conta que estes de toda forma estão inclusos naqueles.

\section{De volta à tradução}

Retomando Berman (2007), vimos que, de acordo com o autor, no caso dos provérbios e expressões idiomáticas, uma forma de não esconder o elemento estrangeiro da obra original, de reconhecer e "receber o Outro enquanto Outro" (p. 68) seria realizar uma tradução próxima à letra, 
procurando manter as imagens, a sonoridade e o jogo dos significantes da expressão ou provérbio. Em outra ocasião, procuramos verificar as possibilidades dessa estratégia tradutória: em Francisco (2009), tentamos aplicá-la na tradução de provérbios e expressões extraídos do romance italiano Fontamara, de Ignazio Silone. Chegamos à conclusão de que, considerando os exemplos com os quais trabalhamos, parece ser viável realizar traduções literais, no sentido proposto por Berman (2007), dessas lexias complexas, pois diversos indícios no contexto ou na própria frase em questão são capazes de levar o leitor a reconhecer o provérbio ou expressão idiomática como tais e a compreender seu sentido.

Apesar disso, pelas obras comentadas a seguir, fica claro não ser essa a estratégia defendida pela maioria dos tradutores e teóricos da tradução ${ }^{5}$. Mais ainda, nota-se que muitos daqueles que se referem à tradução desse tipo de ocorrência simplesmente desconsideram a hipótese de se recorrer a uma tradução que tenda ao sentido literal.

\section{A estratégia predominante: a busca de equivalências}

A leitura de autores que tratam de expressões idiomáticas e provérbios e mencionam suas possibilidades de tradução mostrou ser geralmente privilegiada a utilização, no texto traduzido, de uma expressão ou provérbio da cultura de chegada correspondente quanto ao sentido. No caso de não existir um elemento correspondente composto por imagens semelhantes, prefere-se o uso de uma solução igualmente idiomática com outras imagens e, na inexistência também desta, aceita-se (a contragosto) uma paráfrase explicativa. A recriação de uma expressão ou provérbio calcada na tradução literal não é, em geral, considerada como uma solução boa ou sequer possível.

Podemos começar pela própria autora que nos ajudou a definir os conceitos com os quais estamos trabalhando. Xatara (1998), com base em Diaz, considera equivocado o uso da mesma imagem na tradução quando se trata de uma expressão idiomática cujo equivalente na língua de chegada apresenta uma imagem diversa:

Assim, seria um equivoco interpretar C'est du billard! como um comentário para algo dificil, visto que as associações naturais com o bilhar, que é um jogo difícil, devem evocar o livre deslizar das bolas na superfície plana da mesa: a tradução 'É sopa!', então, representaria mais fielmente a originalidade desse enunciado idiomático com a idéia de "facilidade" (Diaz, 1984). (XATARA, 1998, p. 61)

\footnotetext{
5 Apesar de tratarmos de espaços teóricos distintos, como tradução literária, no caso de Berman (2007) e lexicologia/lexicografia, no caso de Xatara (1994; 1998, 2002) por exemplo, consideramos válidas as comparações estabelecidas, tendo como eixo o tema da tradução de provérbios e expressões idiomáticas, uma vez que tomamos o cuidado de buscar em cada texto as referências específicas às possíveis soluções a que o tradutor pode recorrer, em sua prática tradutória, para lidar com esses elementos.
} 
Embora não se contente, assim como Berman (2007), com a paráfrase explicativa, a autora claramente privilegia o emprego de equivalentes e considera a tradução literal como um "freqüente erro":

O dominio dessas expressões é imprescindivel para o tradutor, não somente porque evita o freqüiente erro de traduzir literalmente os fraseologismos, mas também porque permite eleger entre vários sinônimos o que estilisticamente se aproxima mais do original (Tristá, 1988). Assim, cairá a qualidade da tradução se uma EI do francês, como glisser une peau de banane à quelqu'un, receber em português uma 'explicação', no caso "enganar, lograr, burlar ou ludibriar", ao invés de simples e precisamente sua equivalência idiomática, "puxar o tapete" on "dar uma rasteira"; da mesma forma, "levar vantagem" não deve ser considerada a 'tradução' da EI couper l'herbe sous les pieds à quelqu'un, mas sim "passar a perna". (XATARA, 1998, p. 63)

Por sinal, inclusive a concepção de tradução literal para uma expressão idiomática em Xatara (1998) é diferente daquela de Berman (2007). Para a autora, a tradução literal só seria possível nos casos, pouco frequentes, segundo ela, nos quais existam expressões idênticas nos dois idiomas, com "equivalentes lexicais e manutenção da idiomaticidade, da mesma estrutura (classe gramatical e ordem), do mesmo valor conotativo, do mesmo efeito e do mesmo nível de linguagem", como em "arriver comme un ouragan" / "chegar como um furacão" (ibid., p. 67).

A primeira estratégia discutida por Baker (1992) também é o emprego de um idiomatismo com sentido e forma similares, ou seja, que além de transmitir aproximadamente a mesma ideia também seja constituído por itens lexicais equivalentes, uma combinação pouco frequente segundo a autora. Um dos exemplos apresentados se refere à expressão "to force one's hand", cujo correspondente em francês utiliza a mesma imagem: "forcer la main a qqn."6.

Por sua vez, a tradução não-literal, muito mais comum, segundo Xatara (1998), seria possível em três casos: i) quando existirem idiomatismos semelhantes, embora não exatamente iguais, como "promettre monts et merveilles" / "prometer mundos e fundos"; ii) quando existirem correspondentes idiomáticos completamente diferentes, como "avoir plusieurs cordes à son arc" / "ter muitas cartas na manga"; e iii) quando não há equivalentes, "quando as EI se traduzem por paráfrases", como no caso de "parler comme un oiseau en cage" / "ser palpiteiro". (ibid., 1998, p. 68).

Nota-se que, quando não há equivalentes idiomáticos, admite-se, em último caso, o recurso à paráfrase, mas não é sequer aventada a possibilidade de traduzir literalmente, recriando as características formais da expressão idiomática. Essas posições são reiteradas em outras publicações, como em Xatara, Riva e Rios (2002): "Se identificarmos uma lexia complexa como EI, não devemos nos contentar, na tradução, com uma paráfrase da expressão.

${ }^{6}$ Assim como no português: "forçar a mão". 
Devemos, pois, encontrar uma expressão correspondente que podemos identificar com base em seu significado conotativo" (p. 188). Mas especialmente em Xatara (2002) encontramos um parágrafo que merece ser citado integralmente, no qual a autora estende seu ideal de tradução como substituição por equivalentes também ao caso dos provérbios e contraindica explicitamente a tradução literal.

Le traducteur qui doit "ménager la chèvre et le chou », ne devra pas seulement administrar interesses contraditórios, mais il devra, idiomatiquement, acender uma vela a Deus e outra ao Diabo, ou alors agradar a gregos e troianos, on encore jogar com pau de dois bicos. De la même façon, pour traduire les proverbes « $A u$ royaume des avengles, les borgnes sont rois » et "À brebis tondue, Dieu mesure le vent 》, par exemple, il ne peut pas se satisfaire, respectivement, de l'explication « un médiocre quelconque paraît notable s'il est comparé à des gens sans aucune valeur» ou «Dieu donne les épreuves proportionnelles à la faiblesse bumaine »; le traducteur ne doit pas non plus se contenter de la traduction littérale No reino dos cegos, os caolhos são reis pour le premier proverbe, ou Para ovelha tosquiada, Deus mede o vento pour le deuxième, mais il a à trouver les proverbes équivalents - figés et consacrés: Em terra de cegos, quem tem um olho é rei et Deus dá o frio conforme o cobertor. (p. 442) ${ }^{7}$

Aqui ao menos a possibilidade de tradução literal é concebida. No entanto, o próprio fato de a autora não se preocupar em justificar a recusa das opções literais pode indicar que essa posição raramente seja contestada. Afinal, no texto não são explicitadas as razões para desconsiderar a opção de inserir na cultura de língua portuguesa uma imagem tão original como "Para ovelha tosquiada, Deus mede o vento", ou uma variação enriquecedora como "No reino dos cegos, os caolhos são reis" — ou melhor, "No reino dos cegos, caolhos são reis", para produzir um resultado melhor em relação ao ritmo, como desejaria Berman (2007). E por que não importar uma expressão idiomática como "cuidar da cabra e da couve", já com a aliteração pronta?

Baker (1992) também menciona a tradução por um idiomatismo com significado similar e forma diferente e a tradução por paráfrase como estratégias possíveis e, apesar de também colocar a paráfrase como uma solução na ausência de um equivalente adequado, demonstra uma visão menos

\footnotetext{
${ }^{7} \mathrm{O}$ tradutor que deve ménager la chèvre et le chou, não deve apenas "administrar interesses contraditórios", mas deverá, idiomaticamente, "acender uma vela a Deus e outra ao Diabo", ou então "agradar a gregos e troianos", ou ainda "jogar com pau de dois bicos". Da mesma forma, para traduzir os provérbios Au royaume des aveugles, les borgnes sont rois e $A$ brebis tondue, Dieu mesure le vent, por exemplo, ele não pode se satisfazer, respectivamente, com a explicação "um sujeito medíocre parece notável se comparado com outros sem nenhum valor" ou "Deus dá provações proporcionais à fraqueza humana"; o tradutor também não deve se contentar com a tradução literal "No reino dos cegos, os caolhos são reis" para o primeiro provérbio, ou "Para ovelha tosquiada, Deus mede o vento" para o segundo, mas tem de encontrar os provérbios equivalentes - fixos e consagrados: "Em terra de cegos, quem tem um olho é rei" e "Deus dá o frio conforme o cobertor". (tradução nossa)
} 
negativa em relação a esse recurso. Além disso, a autora menciona possibilidades que não são lembradas por outros estudiosos: a omissão, isto é, o apagamento total do fraseologismo no texto traduzido quando nem um equivalente e nem uma paráfrase seriam possíveis, ou quando a estilística da língua de chegada o exigir, e a compensação, que consistiria na inserção de um fraseologismo em outro ponto do texto para restabelecer o equilíbrio idiomático após ter recorrido à paráfrase ou à omissão. Contudo, a autora também não apresenta nenhuma alternativa comparável à tradução da letra proposta por Berman (2007).

Gonçalves e Sabino (2001) estudam as dificuldades existentes para aprendizes, professores, tradutores, intérpretes, etc. conseguirem dominar as expressões idiomáticas, enfocando aquelas da língua italiana. Analisando diferentes dicionários bilíngues, as autoras apontam diversos problemas nestes, como ausência de determinadas expressões, correspondentes incompletos, correspondentes em português de Portugal, mas não parecem esperar que essas obras disponibilizassem uma tradução literal na qual se compreendesse a imagem utilizada na expressão original. Vejamos alguns exemplos das autoras:

\begin{tabular}{|l|l|l|}
\hline $\begin{array}{l}\text { Expressão } \\
\text { Idiomática }\end{array}$ & $\begin{array}{l}\text { Explicação do } \\
\text { contexto }\end{array}$ & Sugestão de tradução \\
\hline $\begin{array}{l}\text { Dare un colpo al } \\
\text { cerchio e uno alla } \\
\text { botte. }\end{array}$ & $\begin{array}{l}\text { Dar razão a ambos os } \\
\text { contendores. }\end{array}$ & $\begin{array}{l}\text { Agradar a gregos e a troianos; } \\
\text { acender uma vela para Deus e } \\
\text { outra para o Diabo }\end{array}$ \\
\hline $\begin{array}{l}\text { Essere il diavolo e } \\
\text { l'acqua santa. }\end{array}$ & $\begin{array}{l}\text { Diz-se de duas pessoas } \\
\text { que se odeiam. }\end{array}$ & $\begin{array}{l}\text { Ser como o diabo e a cruঞ; ser } \\
\text { como cão e gato. }\end{array}$ \\
\hline $\begin{array}{l}\text { Mettere il bastone fra } \\
\text { le ruote. }\end{array}$ & $\begin{array}{l}\text { Criar dificuldade. Criar } \\
\text { obstáculos. }\end{array}$ & Jogar areia em. \\
\hline
\end{tabular}

(Gonçalves e Sabino, 2001, p. 64)

As sugestões de tradução fornecidas na última coluna são das autoras, que apontam o fato de em alguns dos dicionários analisados só aparecerem as explicações da coluna anterior. Em nenhum momento do trabalho se considera que a tradução literal pudesse interessar a aprendizes, professores ou tradutores. Como para Xatara (1998), na falta de equivalentes, a única opção para as autoras é a paráfrase explicativa: "algumas expressões, por não possuírem uma correspondência adequada na língua-alvo, só podem ser traduzidas por meio de uma definição ou de uma explicação" (GONÇALVES e SABINO, 2001, p. 73, grifo nosso).

Alguns dicionários bilíngues especiais de expressões idiomáticas que consultamos (com diferentes abrangências para esse conceito em cada um, alguns o estendendo até mesmo a provérbios e ditados) confirmam a visão de que diante de tais lexias complexas a primeira providência é procurar um equivalente e, na inexistência deste, só resta explicar o seu sentido. Schambil e 
Schambil (2002), por exemplo, avisam em sua apresentação que "cada verbete contém uma tradução ou explicação em português, seguida de sentençasmodelo que exemplificam o uso da expressão no inglês contemporâneo, e sugestões para o seu uso" (p. 8). Vejamos dois verbetes de páginas iniciais da obra, um com um provérbio (chamado pelos autores de ditado) e o outro com uma expressão idiomática:

ACTIONS

actions speak louder than words - (ditado) Falar é fácil, fazęer é que são elas. $\square$ Every new government has promised to improve the situation of the elderly. I only believe it when I see it. Actions speak louder than words. $A D A M$

not know someone from Adam - nunca ter visto alguém mais gordo, não ter a menor idéia de quem é alguém. $\square$ "Who is that woman that keeps smiling at you?" "I have no idea, I don't know her from Adam.” $\square$ How am I supposed to meet Mr.

Walton amongst all the passengers arriving from Boston when I don't know him from Adam? (p. 21-22)

Também em Gomes (2003), dicionário bastante interessante no qual o conceito de expressão idiomática é extremamente amplo, pois inclui desde provérbios e ditados até verbos frasais e neologismos, observamos uma organização semelhante ao localizar expressões idiomáticas que se enquadram no conceito com o qual trabalhamos aqui. Para "not know someone from Adam", por exemplo, também encontramos o equivalente "nunca ter visto mais gordo", além da explicação "desconhecer totalmente" (GOMES, 2003, p. 5).

Convém destacar que não estamos afirmando que os dicionários devessem deixar de oferecer equivalentes, substituindo-os por traduções literais das expressões idiomáticas e provérbios. O que estamos procurando destacar é que a maioria dos autores, ao pensar em dicionários especializados nessas lexias como ferramentas de auxílio à tradução, consideram serem as equivalências a melhor ajuda que o tradutor pode neles encontrar. Da mesma forma, ao elaborar tais obras, os lexicógrafos assumem essa mesma ideia. Acreditamos que, se a prática de tradução desses itens deixasse de ser monopolizada pelo recurso a equivalentes, os dicionários poderiam prestar uma valiosa assistência informando a sua tradução literal. Continuaria, entretanto, válida a inclusão de equivalentes, de modo a facilitar a compreensão do sentido do original e a fornecer soluções a quem ainda optasse pela tradução por meio da equivalência.

Uma exceção em relação à regra observada parece ser a obra de Steinberg (2002). Nela, a autora lista 1001 provérbios ingleses e norteamericanos e, para cada um deles, fornece uma "tradução tão literal quanto possível” (p. 14), seguida, se houver, de um equivalente. Ruptura ainda maior representa o fato de, na ausência de equivalentes, a autora na maioria das vezes 
não explicar o sentido do provérbio, deixando ao leitor o papel de interpretar a imagem pintada nele. No prefácio, Alfredo Bosi aponta precisamente a vantagem da presença dessa tradução literal:

A literalidade, no caso, é de rigor, pois através dela pode-se cotejar a frase, assim transposta, com o provérbio correspondente em nossa língua. Na comparação ressaltam os torneios peculiares a cada idioma e reponta aquele não sei quê chamado com sal e propriedade pelos velhos filólogos de "gênio da lingua". (BOSI, 2002, p. 4)

É justamente esse "gênio da língua" que transpareceria na estratégia de tradução proposta por Berman (2007). Obviamente, não é razoável esperar que algum dicionário apresente a tradução da "letra" defendida por esse autor, recriando características formais do provérbio ou da expressão original, mas uma tradução literal como a fornecida por Steinberg (2002) pode bem servir de base para que o tradutor a construa.

Como afirmamos, todavia, essa obra e o trecho citado do prefácio de Alfredo Bosi representam uma exceção, pelo que temos observado. Já no prefácio, escrito pelo tradutor e teórico da tradução José Paulo Paes, do dicionário de Camargo e Steinberg (1989), obra de cuja elaboração a mesma autora participa, encontramos o seguinte trecho, referindo-se aos trabalhos dos autores, dentre os quais a primeira edição dos 1001 provérbios em contraste de Steinberg (2002) mencionados acima:

Esses três livros vieram enriquecer o instrumental de trabalho dos tradutores brasileiros, facultando-lhes adentrar com passo mais firme o sertão da página-fonte para chegar mais depressa, mas sem cortar caminho, ao oásis da página-alvo. Cortar caminho, em tradução, significa quase sempre privar o leitor de alguns dos maiores encantos da travessia do texto. Isso acontece sobretudo quando, por não encontrar na lingua-alvo equivalente adequado para alguma expressão figurada do texto-fonte, o tradutor se contenta em verterIhe apenas o significado, sem fazer justiça ao torneio verbal. Em tal pecado incorreria, por exemplo, quem diante de um idiomatismo tão saboroso quanto o nosso "descascar o abacaxi", se contentasse em prosaicamente traduizi-lo por "to solve a rough problem", deslembrado ou ignorante de que existe em inglês idiomatismo equivalente, não menos saboroso, qual seja "to handle a hot potato". (PAES, 1989, p. V-VI)

Ou seja, para Paes (1989), o principal serviço prestado por esses livros ao tradutor é proporcionar equivalentes e, apesar de o autor considerar "descascar o abacaxi” um idiomatismo saboroso, não concebe a possibilidade de introduzi-lo na cultura de língua inglesa.

Por fim, outro teórico da tradução e tradutor consagrado, Paulo Rónai, que toca no tema ao tratar das metáforas, incluindo as expressões idiomáticas no que ele chama de "metáforas convencionais", demonstra posicionamento semelhante, constatável nos dois trechos a seguir: 
Ai do tradutor que não identifica a metáfora convencional e a verte dissecada em seus elementos. "Não ter papas na língua", "vir com quatro pedras na mão" assim como avoir du poil dans le nez ou faire des gorges chaudes se aplicam a situações dissociadas por inteiro, respectivamente, de "papa", de "pedra", de "nariz" e de "calor". (RÓNAI, 1981,

Em todo caso, o problema das metáforas lembra-nos mais uma vez que não estamos traduzindo palavras, mas sentenças. Noutros termos: o bom tradutor, depois de se inteirar do conteúdo de um enunciado, tenta esquecer as palavras em que ele está expresso, para depois procurar, na sua língua, as palavras exatas em que semelhante idéia seria naturalmente vazada. (ibid, p. 58, grifo nosso)

\section{Considerações finais}

Observamos no presente trabalho que a estratégia de tradução da letra dos provérbios e expressões idiomáticas proposta por Berman (2007) representa uma ruptura em relação à prática tradutória mais usual e à maioria das teorias a respeito. Vimos que a maior parte dos tradutores e teóricos mencionados encara a busca de um equivalente na língua de chegada como o melhor procedimento diante de uma dessas lexias complexas. Mais ainda, pudemos constatar que a opção de oferecer uma tradução literal é sistematicamente descartada pela maioria, de modo que, na ausência de um equivalente, enxergam como única saída conformar-se, como aceitando uma derrota, com uma paráfrase explicativa.

Não pretendemos afirmar aqui que a melhor maneira de traduzir expressões idiomáticas e provérbios seja literalmente. Seria passar de um extremo a outro. Apesar de Berman (2007) oferecer razões contundentes para a adoção dessa estratégia, consideramos ser bastante arriscado tentar estabelecer "receitas" aplicáveis à tradução de qualquer texto, mesmo restringindo seu alcance à tradução literária ou à tradução da "grande prosa", como sustenta Berman (2007, p. 46).

Acreditamos, sim, que todo monopólio é prejudicial, especialmente em relação à cultura, e que a sugestão de Berman (2007) pode ter efeitos bastante interessantes, os quais, entretanto, somente poderão ser melhor verificados e avaliados se testados pelos tradutores em seus trabalhos. E isso dificilmente ocorrerá enquanto a tradição e a teoria a respeito continuarem condenando ou, quase sempre, descartando completamente tal possibilidade.

Reginaldo Francisco UFSC franciscotradutor@gmail.com 


\section{Referências}

BAKER, M. In Other Words: A Coursebook on Translation. London: Routledge, 1992.

BERMAN, A. A tradução e a letra ou o albergue do longínquo. Trad. Marie-Hélène Catherine Torres, Mauri Furlan e Andréia Guerini. Rio de Janeiro: 7Letras/PGET-UFSC, 2007.

BOSI, A. Os trabalhos de Martha. In: STEINBERG, M. 1001 provérbios em contraste: ditados ingleses e norte-americanos e seus equivalentes em português. São Paulo: Nova Alexandria, 2002. p. 4-10.

CAMARGO, S.; STEINBERG, M. Dicionário de expressões idiomáticas metafóricas português-inglês. São Paulo: EPU, 1989.

FERRAZ, A. P.; SOUZA, K. C. de. O uso de expressões idiomáticas em textos publicitários. Maestria, Sete Lagoas, n. 2, p. 143-153, jan./dez. 2004. Disponível em: <http://www.unifemm.edu.br/publicacoes/arquivos/Maestria_n2_2004.pdf $>$. Acesso em 28 mar. 2009.

FRANCISCO, R. A tradução da letra dos provérbios e locuções: uma possibilidade de tradução estrangeirizante. In-Traduções, Florianópolis, v. 1, 2009. No prelo.

FRANCISCO, R.; ZAVAGLIA, C. Parece mas não é: as armadilhas na tradução do italiano para o português. São Carlos: Claraluz, 2008.

GOMES, L. L. Novo dicionário de expressões idiomáticas americanas. São Paulo: Pioneira Thomson Learning, 2003.

PAES, J. P. Metáfora e memória. In: CAMARGO, S.; STEINBERG, M. Dicionário de expressões idiomáticas metafóricas português-inglês. São Paulo: EPU, 1989. p. V-VIII.

RÓNAI, P. A tradução vivida. 3. ed. rev. ampl. Rio de Janeiro: Nova Fronteira, 1981.

GONÇALVES, D. C; SABINO, M. A. Desafios enfrentados para obter o domínio das expressões idiomáticas italianas. Fragmentos, Florianópolis, v. 21, p. 61-76, 2001. 
SCHAMBIL, M. H.; SCHAMBIL, P. Dicionário de expressões idiomáticas da língua inglesa. Rio de Janeiro: DIFEL, 2002.

SCHLEIERMACHER, F. "Sobre os diferentes métodos de tradução". Tradução Mauri Furlan, 2007. No prelo.

STEINBERG, M. 1001 provérbios em contraste: ditados ingleses e norteamericanos e seus equivalentes em português. 2.ed. São Paulo: Nova Alexandria, 2002.

SUCCI, T. M. Os provérbios relativos aos sete pecados capitais. $2006.152 \mathrm{f}$. Dissertação (Mestrado em Estudos Linguísticos) - Instituto de Biociências, Letras e Ciências Exatas - Universidade Estadual Paulista, São José do Rio Preto, 2006. Disponível em: <http://www.athena.biblioteca.unesp.br/exlibris/bd/brp/33004153069P5/2 006/succi_tm_me_sjrp.pdf $>$. Acesso em 30 set. 2009.

VENUTI, L. The translator's invisibility: a history of translation. London/New York: Routledge, 1995.

Escândalos da tradução: por uma ética da diferença. Tradução Laureano Pelegrini, et. al. Bauru, SP: EDUSC, 2002.

VINAY, J. P.; DARBELNET, J. Stylistique comparée du francais et de l'anglais. Paris: Didier, 1958.

XATARA, C. M. As expressões idiomáticas de matriz comparativa. 1994. 140 f. Dissertação (Mestrado em Letras: Lingüística e Língua Portuguesa) Faculdade de Ciências e Letras - Universidade Estadual Paulista. Araraquara, 1994.

A tradução para o português de expressões idiomáticas francês. 1998. 254 f. Tese (Doutorado em Letras) - Faculdade de Ciências e Letras - Universidade Estadual Paulista. Araraquara, 1998.

441-444, 2002. Disponível em: . La traduction phraséologique. Meta, Montreal, v. 47, p. $<$ http://www.erudit.org/revue/meta/2002/v47/n3/008029ar.pdf>. Acesso em: 30 jan 2009.

XATARA, C. M.; RIVA, H. C.; RIOS, T. H. C. As dificuldades na tradução de idiomatismos. Cadernos de Tradução, Florianópolis, v. 8, p. 183-194, 2002. Disponível em: 
<http://www.periodicos.ufsc.br/index.php/traducao/article/viewFile/5892/ 5572>. Acesso em: 21 fev. 2009.

XATARA, C. M.; SUCCI, T. M. Revisitando o conceito de provérbio. Veredas on-line, v. 1, p. 33-48, 2008. Disponível em:

$<$ http://www.revistaveredas.ufjf.br/volumes/22/artigo03.pdf $>$. Acesso em: 30 jan. 2009. 